\title{
openheart Impact of beta blockers on patients undergoing transcatheter aortic valve replacement: the OCEAN-TAVI registry
}

\author{
Tetsuya Saito (D) , ${ }^{1}$ Nobuhiro Yoshijima, ${ }^{1}$ Hiromu Hase, ${ }^{1}$ Fumiaki Yashima (D) ,2 \\ Hikaru Tsuruta, ${ }^{1}$ Hideyuki Shimizu, ${ }^{3}$ Keiichi Fukuda, ${ }^{1}$ Toru Naganuma, ${ }^{4}$ \\ Kazuki Mizutani, ${ }^{5}$ Motoharu Araki, ${ }^{6}$ Norio Tada, ${ }^{7}$ Futoshi Yamanaka, ${ }^{8}$ \\ Shinichi Shirai, ${ }^{9}$ Minoru Tabata, ${ }^{10}$ Hiroshi Ueno, ${ }^{11}$ Kensuke Takagi, ${ }^{12}$ \\ Akihiro Higashimori, ${ }^{13}$ Yusuke Watanabe, ${ }^{14}$ Masanori Yamamoto (D) , ${ }^{15,16}$ \\ Kentaro Hayashida ${ }^{1}$
}

\begin{abstract}
- Additional material is published online only. To view please visit the journal online (http://dx.doi.org/10.1136/ openhrt-2020-001269).
\end{abstract}

To cite: Saito T, Yoshijima N, Hase $\mathrm{H}$, et al. Impact of beta blockers on patients undergoing transcatheter aortic valve replacement: the OCEAN-TAVI registry. Open Heart 2020;7:e001269. doi:10.1136/ openhrt-2020-001269

Received 17 February 2020

Revised 24 April 2020

Accepted 8 May 2020
Check for updates

(c) Author(s) (or their employer(s)) 2020. Re-use permitted under CC BY. Published by BMJ.

For numbered affiliations see end of article.

Correspondence to Dr Kentaro Hayashida; khayashida@umin.ac.jp

\section{ABSTRACT}

Objective There is paucity of data on optimal medical treatment, including use of beta blockers for patients undergoing transcatheter aortic valve replacement (TAVR). The study aimed to investigate the association of beta blockers and clinical outcomes following TAVR. Methods We examined data of 2563 patients who underwent TAVR between October 2013 and May 2017 obtained from a prospective multicentre cohort registry, the optimised catheter valvular intervention-TAVI registry. We compared the 2-year cardiovascular and non-cardiovascular mortality and in-hospital outcomes between patients with and without preprocedural betablocker administration by propensity score matching (PSM).

Results Preprocedural beta blockers were prescribed in 867 patients (33.8\%). After PSM, the incidence of inhospital congestive heart failure was significantly lower in patients with preprocedural beta blocker $(p=0.046)$. No differences were found in 2-year cardiovascular and non-cardiovascular mortality. In the subgroup analyses, beta-blocker administration was associated with a lower cardiovascular mortality within 2 years in patients with a history of coronary artery bypass grafting (CABG; logrank $p=0.017$ ), presence of peripheral artery disease ( $\mathrm{PAD}$; log-rank $\mathrm{p}=0.003$ ) and brain natriuretic peptide (BNP) $\geq 400 \mathrm{pg} / \mathrm{mL}$ (log-rank $p=0.003$ ). When stratified by postprocedural left ventricular ejection fraction (postLVEF), beta-blocker administration was associated with a lower cardiovascular mortality among patients with postLVEF $<50 \%$ (log-rank $p=0.024)$.

Conclusions Preprocedural beta-blocker administration was not associated with 2-year cardiovascular and noncardiovascular mortality in overall, but was associated with a lower 2-year cardiovascular mortality in patients with a history of CABG, presence of PAD, BNP $\geq 400 \mathrm{pg} /$ $\mathrm{mL}$ and post-LVEF $<50 \%$. The findings must be validated using randomised trials.

\section{INTRODUCTION}

It is not clear whether medical therapy is advantageous for the treatment of aortic

\section{Key questions}

What is already known about this subject?

- Transcatheter aortic valve replacement (TAVR) is an established therapy for symptomatic patients with severe aortic stenosis. However, the optimal medical therapy, including beta blockers for patients who undergo TAVR, remains unspecified.

What does this study add?

- The study showed that beta-blocker administration was associated with a lower 2-year cardiovascular mortality in patients with a history of coronary artery bypass grafting (CABG; log-rank $\mathrm{p}=0.017$ ), presence of peripheral artery disease (PAD; log-rank $p=0.003$ ), brain natriuretic peptide (BNP) $\geq 400 \mathrm{pg} /$ $\mathrm{mL}$ and postprocedural left ventricular ejection fraction (LVEF) $<50 \%$ (log-rank $p=0.024$ ).

How might this impact on clinical impact?

- This result suggests that beta-blocker administration was associated with good clinical outcomes among patients with a history of CABG, presence of PAD, BNP $\geq 400 \mathrm{pg} / \mathrm{mL}$ and post-procedural LVEF $<50 \%$. The findings need to be confirmed by randomised trials.

stenosis (AS). Several prior studies have shown that renin-angiotensin system (RAS) inhibitors for AS are associated with improved survival. ${ }^{12}$ It is also well known that beta blockers should be carefully administered in cases of severe AS because of their negative inotropic effects. However, there are conflicting reports on survival benefits when beta blockers are used in patients with severe AS. ${ }^{3}$ Beta blockers reduce the haemodynamic and metabolic overload in patients with asymptomatic severe AS. ${ }^{4}$

Transcatheter aortic valve replacement (TAVR) is an established therapy in patients with symptomatic severe AS at high or 
intermediate surgical risk. ${ }^{5-7}$ Recently, the placement of aortic transcatheter valves 3 trial showed that TAVR with a balloon-expandable valve was more effective than surgical aortic valve replacement (SAVR) with respect to the composite endpoint of death, stroke and rehospitalisation at 1 year in patients with severe AS at low surgical risk. ${ }^{8}$ Besides, TAVR with a self-expanding valve was noninferior to SAVR with respect to death or disabling stroke in patients at low surgical risk. ${ }^{9}$ Although the indication of TAVR is expanding based on these studies, there are limited data regarding the optimal medical treatment for patients undergoing TAVR. The use of RAS inhibitors after TAVR has lowered mortality. ${ }^{10}{ }^{11}$ However, the effect of preprocedural beta-blocker administration on these patients remains unclear. Thus, our purpose was to investigate the effect of preprocedural administration of beta blockers on the clinical outcomes of patients with severe AS who underwent TAVR.

\section{METHODS}

\section{Study population}

A total of 2588 patients were enrolled in the Optimised transCathEter vAlvular iNtervention (OCEAN)transcatheter aortic valve implantation (TAVI) registry between October 2013 and May 2017. The OCEANTAVI registry is a prospective, multicentre, observational registry of patients who underwent TAVR using the Edwards Sapien XT/Sapien 3 prosthesis (Edwards Lifesciences, Irvine, California, USA) or Medtronic Corevalve/ Evolut R prosthesis (Medtronic, Minneapolis, Minnesota, USA) at 14 Japanese medical centres. All study participants provided informed consent and the registry was approved by the ethics committees of all participating institutions. Patients or the public were not involved in the design, or conduct, or reporting, or dissemination plans of our research. The OCEAN-TAVI registry was registered with the University Hospital Medical Information Network Clinical Trial Registry and accepted by the International Committee of Medical Journal Editors (UMIN-ID: 000020423). Patients were followed annually at the participating institutions. At that time, blood tests, echocardiography were performed. The events were site reported from the participating institutions and not adjudicated in clinical event adjudication committee. The database was regularly audited by the data committee members to ensure the consistency.

After exclusion of 25 patients owing to conversion to open surgery, 2563 patients participated in this study and were divided based on whether or not they were administered preprocedural beta blockers (figure 1). Preprocedural beta-blocker administration was defined as beta blockers being prescribed at TAVR.

\section{Outcomes}

The primary outcomes were 2-year cardiovascular and non-cardiovascular mortalities after TAVR. For patients who lost to follow-up, we used the last date when survival was confirmed. The secondary outcomes were as follows: in-hospital outcomes and complications and postprocedural echocardiographic data. Cardiovascular mortality and complications were defined based on the Valve Academic Research Consortium (VARC)-2 criteria. $^{12}$ In-hospital congestive heart failure was defined as the requirement of intravenous injection of diuretics or inotropic agents, mechanical support for heart failure, such as intra-aortic balloon pumping (IABP) or extracorporeal membrane oxygenation (ECMO) after TAVR.

\section{Echocardiography}

Transthoracic echocardiography was performed at baseline, before hospital discharge, and at the annual follow-up. All transthoracic echocardiographic parameters were measured according to the guidelines of the

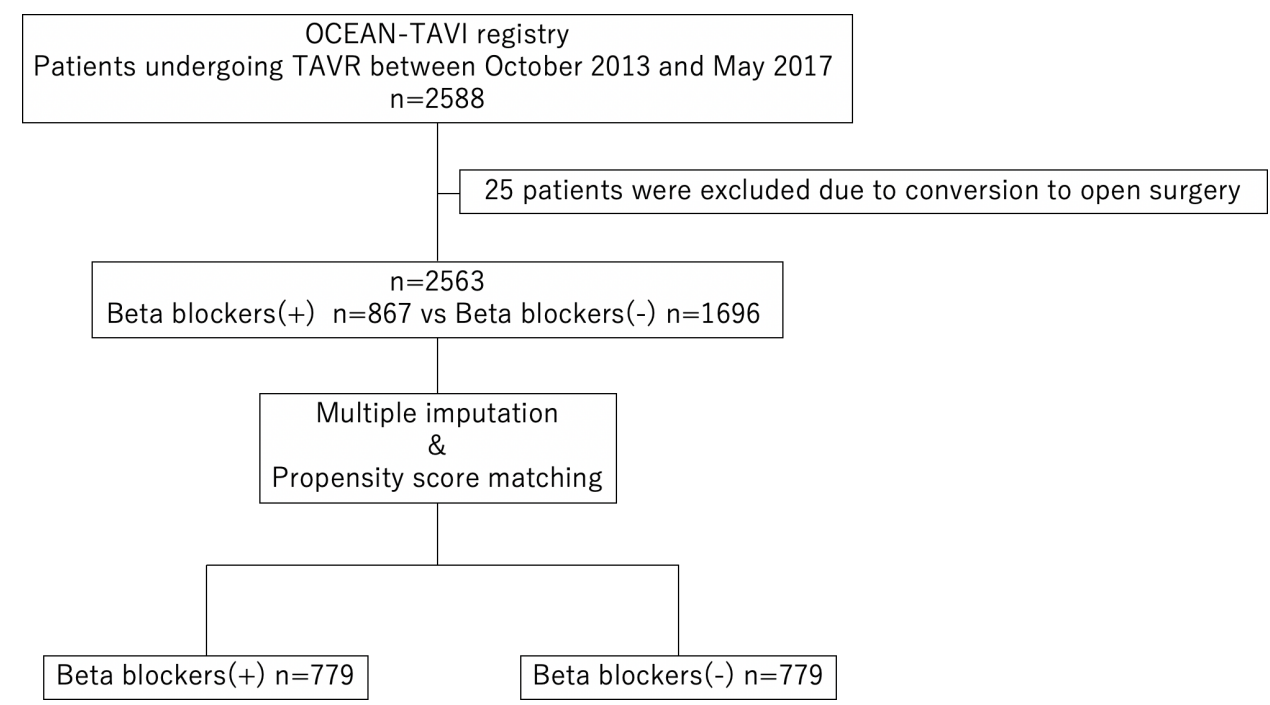

Figure 1 Study flow diagram. Of 2588 patients, 25 patients were excluded due to conversion to open surgery. Beta-blocker $(-)=$ patients without preprocedural beta blockers; beta-blocker $(+)=$ patients with preprocedural beta blockers. OCEAN, Optimised transCathEter vAlvular iNtervention; TAVR, transcatheter aortic valve replacement. 
Valvular heart disease

Table 1 Baseline characteristics

\begin{tabular}{|c|c|c|c|c|}
\hline & Beta-blocker (+) n=867 & Beta-blocker (-) n=1696 & $P$ value & SMD \\
\hline Age, years & 85(82-88) & $85(81-88)$ & 0.91 & 0.005 \\
\hline Male & $262(30.2)$ & $527(31.1)$ & 0.66 & 0.019 \\
\hline Body mass index, $\mathrm{kg} / \mathrm{m}^{2}$ & $21.9(19.4-24.4)$ & $22.1(19.7-24.3)$ & 0.44 & 0.032 \\
\hline Body surface area, $\mathrm{m}^{2}$ & $1.40(1.30-1.52)$ & $1.41(1.30-1.54)$ & 0.28 & 0.045 \\
\hline NYHA 3 or 4 & $479(55.2)$ & $827(48.8)$ & 0.002 & 0.13 \\
\hline Hypertension & $691(79.7)$ & $1280(75.5)$ & 0.016 & 0.1 \\
\hline Dyslipidaemia & $375(43.3)$ & $729(43.0)$ & 0.896 & 0.005 \\
\hline Diabetes mellitus & $196(22.6)$ & $351(20.7)$ & 0.26 & 0.046 \\
\hline Chronic kidney disease & $645(74.4)$ & $1146(67.6)$ & $<0.001$ & 0.15 \\
\hline Previous ischaemic stroke & $78(9.0)$ & $205(12.1)$ & 0.018 & 0.1 \\
\hline Previous haemorrhagic stroke & $3(0.3)$ & $9(0.5)$ & 0.52 & 0.028 \\
\hline COPD & $138(15.9)$ & $243(14.3)$ & 0.29 & 0.044 \\
\hline Peripheral artery disease & $145(16.7)$ & $227(13.4)$ & 0.023 & 0.093 \\
\hline Coronary artery disease & $349(40.3)$ & $597(35.2)$ & 0.012 & 0.1 \\
\hline Previous CABG & $71(8.2)$ & $98(5.8)$ & 0.02 & 0.095 \\
\hline Atrial fibrillation & 227 (26.2) & $316(18.6)$ & $<0.001$ & 0.18 \\
\hline Permanent pacemaker & $70(8.1)$ & $96(5.7)$ & 0.019 & 0.096 \\
\hline Liver disease & $27(3.1)$ & $49(2.9)$ & 0.75 & 0.013 \\
\hline Active cancer & $43(5.0)$ & $81(4.8)$ & 0.84 & 0.009 \\
\hline Clinical frail score & & & 0.36 & 0.060 \\
\hline $1-4$ & $655(75.5)$ & $1237(72.9)$ & & \\
\hline 5,6 & $180(23.1)$ & $392(23.1)$ & & \\
\hline 7,8 & $32(3.7)$ & $67(4.0)$ & & \\
\hline STS score, $\%$ & $6.96(4.84-10.2)$ & $6.30(4.35-9.24)$ & $<0.001$ & 0.063 \\
\hline Logistic EuroScore, \% & $13.6(8.83-22.1)$ & $12.7(8.10-20.5)$ & 0.011 & 0.069 \\
\hline Euro II score, \% & $4.06(2.61-6.30)$ & $3.57(2.24-5.87)$ & 0.001 & 0.037 \\
\hline \multicolumn{5}{|l|}{ Medication } \\
\hline RAS inhibitors & $484(55.8)$ & $889(52.4)$ & 0.1 & 0.068 \\
\hline Ca blockers & $376(43.4)$ & $749(44.2)$ & 0.7 & 0.016 \\
\hline Digoxin & $22(2.5)$ & $66(3.9)$ & 0.075 & 0.077 \\
\hline Any diuretic therapy & $570(65.7)$ & $801(47.2)$ & $<0.001$ & 0.38 \\
\hline Statin & $380(43.8)$ & $678(40.0)$ & 0.061 & 0.078 \\
\hline \multicolumn{5}{|l|}{ Laboratory } \\
\hline $\mathrm{Na}, \mathrm{mEq} / \mathrm{L}$ & $140(138-142)$ & $140(138-142)$ & 0.55 & 0.002 \\
\hline $\mathrm{Hb}, \mathrm{g} / \mathrm{L}$ & $110(100-123)$ & $113(102-125)$ & 0.022 & 0.081 \\
\hline eGFR, $\mathrm{mL} / \mathrm{min} / 1.73 \mathrm{~m}^{2}$ & $47.6(35.1-60.1)$ & $51.7(39.0-64.1)$ & $<0.001$ & 0.2 \\
\hline Albumin, g/dL & $3.80(3.40-4.00)$ & $3.80(3.50-4.10)$ & 0.005 & 0.11 \\
\hline Albumin $<3.5 \mathrm{~g} / \mathrm{dL}$ & $223(25.7)$ & $383(22.6)$ & 0.077 & 0.073 \\
\hline Brain natriuretic peptide, $\mathrm{pg} / \mathrm{mL}$ & $355(169-666)$ & $231(103-515)$ & $<0.001$ & 0.18 \\
\hline Brain natriuretic peptide $\geq 400 \mathrm{pg} / \mathrm{mL}$ & $322(45.2)$ & $499(32.8)$ & $<0.001$ & 0.26 \\
\hline \multicolumn{5}{|c|}{ Preprocedural echocardiographic data/computed tomographic data } \\
\hline Aortic valve are, $\mathrm{cm}^{2}$ & $0.61(0.50-0.73)$ & $0.63(0.51-0.75)$ & 0.033 & 0.086 \\
\hline Peak velocity, $\mathrm{m} / \mathrm{s}$ & $4.40(4.00-4.98)$ & $4.58(4.10-5.12)$ & $<0.001$ & 0.22 \\
\hline Mean pressure gradient, mm Hg & $45.5(36.0-57.7)$ & $49.0(39.0-63.0)$ & $<0.001$ & 0.22 \\
\hline LV end-diastolic diameter, mm & $44.0(39.5-49.0)$ & $43.8(40.0-48.0)$ & 0.88 & 0.035 \\
\hline LV end-systolic diameter, mm & $28.3(25.0-34.1)$ & $28.0(24.5-32.4)$ & 0.012 & 0.12 \\
\hline
\end{tabular}




\begin{tabular}{|c|c|c|c|c|}
\hline & Beta-blocker (+) n=867 & Beta-blocker (-) n=1696 & $P$ value & SMD \\
\hline Left atrial diameter, mm & $43.0(37.9-47.0)$ & $41.1(37.1-46.0)$ & 0.004 & 0.089 \\
\hline LVEF, \% & $61.0(51.0-66.9)$ & $63.0(53.1-68.1)$ & $<0.001$ & 0.15 \\
\hline LVEF $<50 \%$ & $201(23.2)$ & $324(19.1)$ & 0.016 & 0.099 \\
\hline Indexed stroke volume, $\mathrm{mL} / \mathrm{m}^{2}$ & $42.5(33.2-52.7)$ & $45.4(36.9-54.4)$ & $<0.001$ & 0.22 \\
\hline Indexed stroke volume $<35 \mathrm{~mL} / \mathrm{m}^{2}$ & $213(29.6)$ & $281(20.2)$ & $<0.001$ & 0.22 \\
\hline $\mathrm{AR} \geq$ moderate & $98(11.3)$ & $176(10.4)$ & 0.48 & 0.03 \\
\hline $\mathrm{MR} \geq$ moderate & $118(13.6)$ & $170(10.0)$ & 0.007 & 0.11 \\
\hline Bicuspid & $23(2.7)$ & $41(2.4)$ & 0.72 & 0.015 \\
\hline Annulus area, $\mathrm{mm}^{2}$ & 389 (346-442) & $390(349-439)$ & 0.75 & 0.01 \\
\hline SOV mean diameter, mm & $29.3(27.6-31.4)$ & $29.4(27.6-31.5)$ & 0.4 & 0.024 \\
\hline \multicolumn{5}{|l|}{ Procedural data } \\
\hline Transfemoral approach & $700(80.7)$ & $1446(85.3)$ & 0.003 & 0.12 \\
\hline Elective & 810 (93.4) & 1604 (94.6) & 0.95 & 0.048 \\
\hline Local anaesthesia & $206(23.8)$ & 401 (23.6) & 0.65 & 0.003 \\
\hline
\end{tabular}

AR, aortic regurgitation; CABG, coronary artery bypass grafting; COPD, chronic obstructive pulmonary disease; eGFR, estimated glomerular filtration rate; Hb, haemoglobin; LV, left ventricular; LVEF, left ventricular ejection fraction; MR, mitral regurgitation; NYHA, New York Heart Association; RAS, renin-angiotensin system; SMD, standardised mean difference; SOV, sinus of Valsalva; STS, Society of Thoracic Surgeons Predicted Risk of Mortality.

American Society of Echocardiography. ${ }^{13} 14$ The degree of paravalvular leak (PVL) was measured in accordance with the VARC-2 criteria and reported as a semiquantitative grade: none, trace, mild, moderate and severe. Prosthesis-patient mismatch (PPM) was defined as an indexed effective orifice area $<0.85 \mathrm{~cm}^{2} / \mathrm{m}^{2}$ according to the VARC-2 criteria.

\section{Statistical analysis}

We compared baseline characteristics between patients with and without preprocedural administration of beta blockers (table 1). Continuous variables are presented as medians and IQRs $(25 \%-75 \%)$ and compared using the Student's t-test or Mann-Whitney U test. Categorical variables are presented as means and percentages and compared using the Pearson's $\chi^{2}$ test or Fisher's exact test.

Baseline variables are listed in table 1 . There were missing data for baseline variables. Percentage of missing data for baseline variables are shown in online supplementary table 1 . There were no missing data for baseline variables not in online supplementary table 1 . Multiple imputation was performed to properly handle missing data. Missing continuous variables were imputed using the predictive mean matching method. Missing binary variables were imputed using logistic regression models. We created 20 imputed datasets. Propensity score matching (PSM) was performed after multiple imputations to reduce imbalances at baseline between the groups. The covariates included in the model are listed in table 1 . Propensity scores were calculated within each imputed dataset using logistic regression models to estimate the probability of preprocedural beta-blocker prescription. Propensity scores were averaged across the imputed datasets for each patient. PSM was performed with a 1:1 matching protocol without replacement by the averaged propensity scores. The calliper width was 0.2 of the SD of the logit of the averaged propensity scores. Balance between the two groups was assessed by absolute standardised mean difference (SMD).

Cumulative incidences were calculated using the Kaplan-Meier method in the matched cohort. The logrank test was performed to compare cardiovascular mortality between patients with and without preprocedural administration of beta blockers.

To identify the groups for which beta blockers were effective, subgroup analyses for cardiovascular mortality were performed for age ( $\geq 80$ or $<80$ years), sex, chronic kidney disease (CKD), atrial fibrillation (AF), coronary artery disease $(\mathrm{CAD})$, coronary artery bypass grafting $(\mathrm{CABG})$, peripheral artery disease $(\mathrm{PAD})$, preprocedural left ventricular ejection fraction (pre-LVEF; $\geq 50 \%$ or $<50 \%$ ), preprocedural aortic regurgitation (AR; $\geq$ moderate or $\leq$ mild), preprocedural mitral regurgitation (MR; $\geq$ moderate or $\leq$ mild) and brain natriuretic peptide (BNP; $\geq 400 \mathrm{pg} / \mathrm{mL}$ or $<400 \mathrm{pg} / \mathrm{mL}$ ). In subgroup analyses for cardiovascular mortality, patients with BNP $\geq$ $400 \mathrm{pg} / \mathrm{mL}$ were focused because it is said that there is a high possibility of heart failure if $\mathrm{BNP} \geq 400 \mathrm{pg} / \mathrm{mL} \cdot{ }^{1516} \mathrm{In}$ addition, we performed the subgroup analysis for cardiovascular mortality in the subset of PPM and PVL.

To confirm the safety of beta blockers for patients undergoing TAVR, subgroup analyses for non-cardiovascular mortality were performed for age ( $\geq 80$ or $<80$ years), sex, body mass index $\left(\geq 20 \mathrm{~kg} / \mathrm{m}^{2}\right.$ or $\left.<20 \mathrm{~kg} / \mathrm{m}^{2}\right)$, New 
A

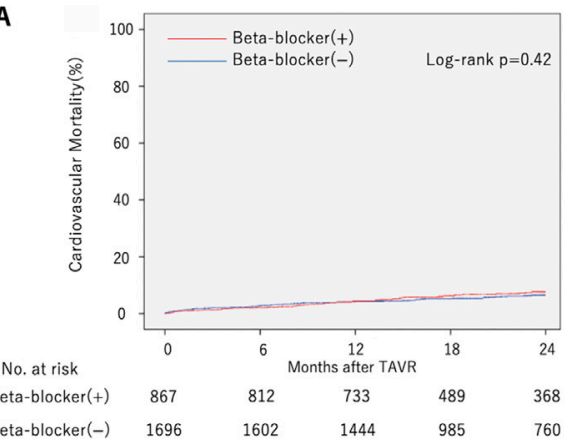

B

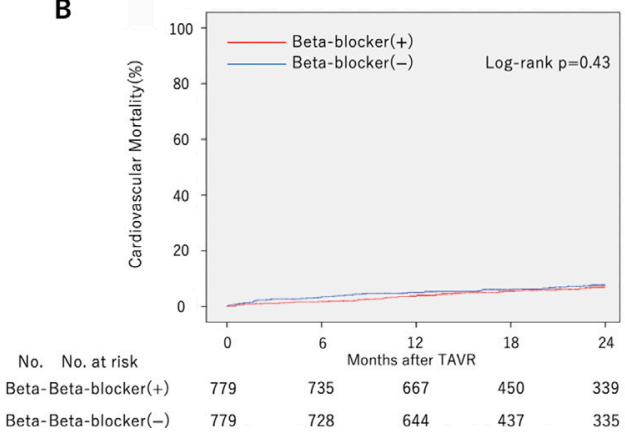

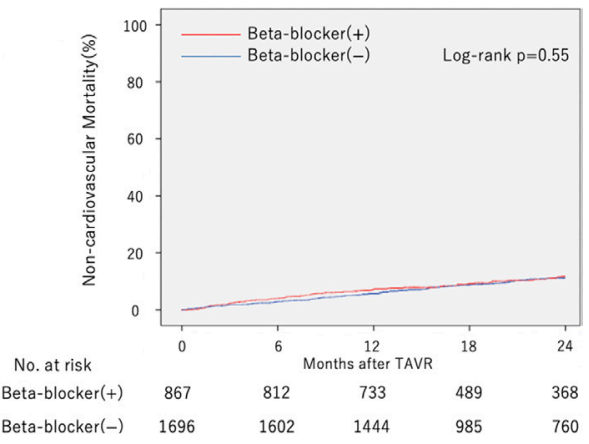

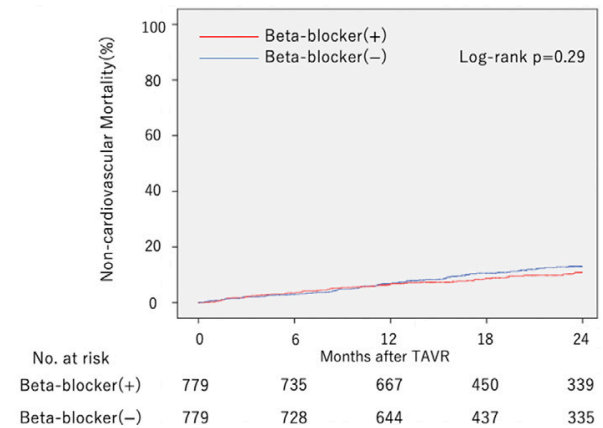

Figure 2 Kaplan-Meier curves of cardiovascular mortality and non-cardiovascular mortality in the non-matched and matched cohort. Two-year cardiovascular mortality and non-cardiovascular mortality of patients with beta-blocker administration compared with those without in the $(A)$ non-matched and $(B)$ matched cohort. TAVR, transcatheter aortic valve replacement.

York Heart Association (NYHA) class $(1,2$ or 3,4$)$, CKD, $\mathrm{PAD}$, chronic obstructive pulmonary disease (COPD), albumin levels $(\geq 3.5 \mathrm{~g} / \mathrm{dL}$ or $<3.5 \mathrm{~g} / \mathrm{dL})$ and clinical frail score $(1-4,5-6$ or $\geq 7)$. Interaction tests between each covariate were performed. PSM after multiple imputation was performed in the subgroups with $\mathrm{p}$ for interaction $<0.05$. We selected the subgroup from the original data including 2563 patients, then performed PSM for preprocedural beta blockers because the baseline characteristic between beta-blocker group and non-beta-blocker group would be consistent in the subgroup. The log-rank test was performed to evaluate cardiovascular mortality between patients with and without preprocedural betablocker administration in the subgroups.

It was hypothesised that the effect of beta blockers on cardiovascular mortality would be influenced by LVEF. Therefore, the original data were divided according to preLVEF ( $\geq 50 \%$ or $<50 \%$ ), the postprocedural LVEF (postLVEF; $\geq 50 \%$ or $<50 \%$ ). PSM for preprocedural beta-blocker administration was performed in each group. The log-rank test was performed to evaluate cardiovascular mortality.

All statistical analyses were performed using SPSS V.23.0 (IBM SPSS Statistics, IBM Corporation) and R software V.3.5.2 (Vienna, Austria). All tests were two sided and statistical significance was set at $\mathrm{p}<0.05$.

\section{RESULTS}

\section{Baseline characteristics}

The baseline characteristics of the study participants are shown in table 1. Among 2563 patients, beta blockers were administered to 867 patients (33.8\%) before TAVR despite the presence of severe AS (figure 1). There were statistically significant differences between patients with and without beta-blocker administration with regard to NYHA class 3 or 4 , history of ischaemic stroke, CABG, presence of hypertension, CKD, PAD, CAD, AF, implantation of permanent pacemaker, Society of Thoracic Surgeons Predicted Risk of Mortality score, Logistic Euro score, Euro II score, any diuretic therapy, haemoglobin, estimated glomerular filtration rate, albumin levels, BNP, aortic valve area, peak velocity, mean pressure gradient, LV end-systolic diameter, left atrial diameter, LVEF, indexed stroke volume, MR $\geq$ moderate and the transfemoral approach.

\section{Primary outcomes in the matched cohort}

A total of 1558 patients were matched (online supplementary table 2). After performing PSM, the absolute SMD value was lower than 0.1 in all examined covariates.

Kaplan-Meier curves of cardiovascular and noncardiovascular mortality in the non-matched and matched cohort are shown in figure 2. Follow-up rate at 2 years was $92.1 \%$. The median follow-up period in the matched cohort was 658 days (IQR 381-863). Ninety-five patients died of cardiovascular causes and 154 of noncardiovascular causes during the follow-up period in the matched cohort. There was no significant difference between the two groups regarding cardiovascular (logrank $\mathrm{p}=0.43$ ) and non-cardiovascular mortality (log-rank $\mathrm{p}=0.29)$ in the matched cohort. 


\begin{tabular}{|c|c|c|c|}
\hline & Beta-blocker (+) n=779 & Beta-blocker (-) $n=779$ & $P$ value \\
\hline \multicolumn{4}{|l|}{ Procedural outcomes } \\
\hline 30-day mortality & $8(1.0)$ & $14(1.8)$ & 0.19 \\
\hline Procedural Ml & $6(0.8)$ & $1(0.1)$ & 0.12 \\
\hline Ischaemic stroke & $13(1.7)$ & $15(1.9)$ & 0.7 \\
\hline Haemorrhagic stroke & $1(0.1)$ & $3(0.4)$ & 0.32 \\
\hline Bleeding & $190(24.4)$ & $192(24.6)$ & 0.91 \\
\hline AKI & $91(11.7)$ & $93(11.9)$ & 0.88 \\
\hline Vascular complication & $74(9.5)$ & $68(8.7)$ & 0.59 \\
\hline New permanent pacemaker & $56(7.2)$ & $74(9.5)$ & 0.099 \\
\hline New onset AF & $34(4.4)$ & $24(3.1)$ & 0.19 \\
\hline Congestive heart failure & $34(4.4)$ & $52(6.7)$ & 0.046 \\
\hline \multicolumn{4}{|l|}{ Postprocedural echocardiographic data } \\
\hline LVEF, \% & $62.0(54.0-67.0)$ & $62.1(54.0-67.4)$ & 0.49 \\
\hline LVEF $<50 \%$ & $141(18.3)$ & $122(15.9)$ & 0.21 \\
\hline THV peak velocity, $\mathrm{m} / \mathrm{s}$ & $2.15(1.90-2.47)$ & $2.20(1.93-2.50)$ & 0.095 \\
\hline THV mean pressure gradient, $\mathrm{mm} \mathrm{Hg}$ & $9.4(7.4-12.9)$ & $10.0(7.3-13.0)$ & 0.13 \\
\hline Indexed EOA, $\mathrm{cm}^{2} / \mathrm{m}^{2}$ & $1.15(0.97-1.36)$ & $1.13(0.95-1.31)$ & 0.13 \\
\hline PPM & $94(12.4)$ & $85(11.3)$ & 0.52 \\
\hline PVL & & & 0.34 \\
\hline None & $140(18.0)$ & $127(16.4)$ & \\
\hline Trace & $366(47.0)$ & $377(48.6)$ & \\
\hline Mild & $252(32.4)$ & $259(33.4)$ & \\
\hline Moderate & $20(2.6)$ & $11(1.4)$ & \\
\hline Severe & $1(0.1)$ & $0(0.0)$ & \\
\hline $\mathrm{PVL} \geq$ moderate & $20(2.6)$ & $12(1.5)$ & 0.16 \\
\hline
\end{tabular}

AF, atrial fibrillation; AKI, acute kidney injury; EOA, effective orifice area; LVEF, left ventricular ejection fraction; MI, myocardial infarction; PPM, prosthesis-patient mismatch; PVL, paravalvularleak; THV, transcatheter heart valve.

\section{Secondary outcomes in the matched cohort}

Regarding the matched cohort, in-hospital patient outcomes, complications and postprocedural echocardiographic data are shown in table 2. The incidence of in-hospital congestive heart failure was lower among patients treated with beta blockers than among those treated without $(\mathrm{p}=0.046)$.

\section{Subgroup analyses}

Subgroup analyses for cardiovascular mortality are shown in figure 3 . The groups with a significant difference were history of CABG ( $p$ for interaction=0.035), presence of PAD ( $\mathrm{p}$ for interaction $=0.026)$ and BNP $(\mathrm{p}$ for interaction $=0.005$ ). Based on this result, PSM was performed in the groups. Kaplan-Meier curves of cardiovascular mortality in each group are shown in figure 4. Beta-blocker administration was associated with a significantly lower 2-year cardiovascular mortality in patients with $\mathrm{CABG}$ history (log-rank $\mathrm{p}=0.017$ ), presence of PAD (log-rank $\mathrm{p}=0.003$ ) and $\mathrm{BNP} \geq 400 \mathrm{pg} / \mathrm{mL}$ (logrank $\mathrm{p}=0.003$ ). Subgroup analyses for cardiovascular mortality in the subset of PPM and PVL are shown in online supplementary figure 1 . There was no interaction between beta blockers and PPM ( $p$ for interaction=0.15), beta blocker and PVL ( $\mathrm{p}$ for interaction=0.34).

Subgroup analyses for non-cardiovascular mortality are shown in figure 5. Interaction between COPD and beta-blocker administration was noted ( $p$ for interaction $=0.035$ ).

\section{Cardiovascular mortality stratified by LVEF}

Kaplan-Meier curves of cardiovascular mortality in each group (pre-LVEF $\geq 50 \%$ or $<50 \%$, post-LVEF $\geq 50 \%$ or $<50 \%$ ) are shown in figure 6 . The administration of beta blockers to patients with post-LVEF $<50 \%$ was associated with a lower 2-year cardiovascular mortality (log-rank $\mathrm{p}=0.024)$. In patients with pre-LVEF $\geq 50 \%$, pre-LVEF $<50 \%$ and post-LVEF $\geq 50 \%$, there was no significant difference in cardiovascular mortality between the groups with or without beta-blocker administration (log-rank $\mathrm{p}=0.61$ in patients with pre-LVEF $\geq 50 \%, \log$-rank $\mathrm{p}=0.22$ in patients with pre-LVEF $<50 \%$ and log-rank $\mathrm{p}=0.75$ in patients with post-LVEF $\geq 50 \%$ ). 


\begin{tabular}{|c|c|c|c|}
\hline \multirow[t]{2}{*}{ Subgroup } & \multirow[t]{2}{*}{ No. of patients } & \multicolumn{2}{|c|}{ No. of event/total no. of patients } \\
\hline & & Beta-blocker(-) & Beta-blocker $(+)$ \\
\hline Overall & 1558 & $51 / 779$ & $44 / 779$ \\
\hline Age $<80 y$ rs & 221 & $12 / 113$ & $8 / 108$ \\
\hline Age $\geqq 80$ yrs & 1337 & $39 / 666$ & $36 / 671$ \\
\hline Male & 471 & $23 / 232$ & $18 / 239$ \\
\hline Female & 1087 & $28 / 547$ & $26 / 540$ \\
\hline CKD - & 428 & $10 / 217$ & $10 / 211$ \\
\hline CKD+ + & 1130 & $41 / 562$ & $34 / 568$ \\
\hline AF - & 1196 & $37 / 600$ & $33 / 596$ \\
\hline$A F+$ & 362 & $14 / 179$ & $11 / 183$ \\
\hline CAD- & 949 & $26 / 476$ & $22 / 473$ \\
\hline$C A D+$ & 609 & $25 / 303$ & $22 / 306$ \\
\hline Previous CABG- & 1439 & $36 / 716$ & 49/723 \\
\hline Previous CABG+ & 119 & $15 / 63$ & $5 / 56$ \\
\hline PAD- & 1308 & $34 / 655$ & $38 / 653$ \\
\hline PAD+ & 250 & $17 / 124$ & $6 / 126$ \\
\hline LVEF $\geq 50 \%$ & 1226 & $35 / 611$ & $34 / 615$ \\
\hline LVEF $<50 \%$ & 332 & $16 / 168$ & $10 / 164$ \\
\hline AR $\leq$ mild & 1386 & $45 / 687$ & $40 / 699$ \\
\hline$A R \geq$ moderate & 172 & $6 / 92$ & $4 / 80$ \\
\hline MR $\leq$ mild & 1371 & $42 / 681$ & $40 / 690$ \\
\hline$M R \geq$ moderate & 187 & 9/98 & $4 / 89$ \\
\hline BNP $<400 \mathrm{pg} / \mathrm{ml}$ & 763 & $15 / 388$ & $24 / 375$ \\
\hline $\mathrm{BNP} \geq 400 \mathrm{pg} / \mathrm{ml}$ & 546 & $26 / 280$ & $11 / 266$ \\
\hline
\end{tabular}
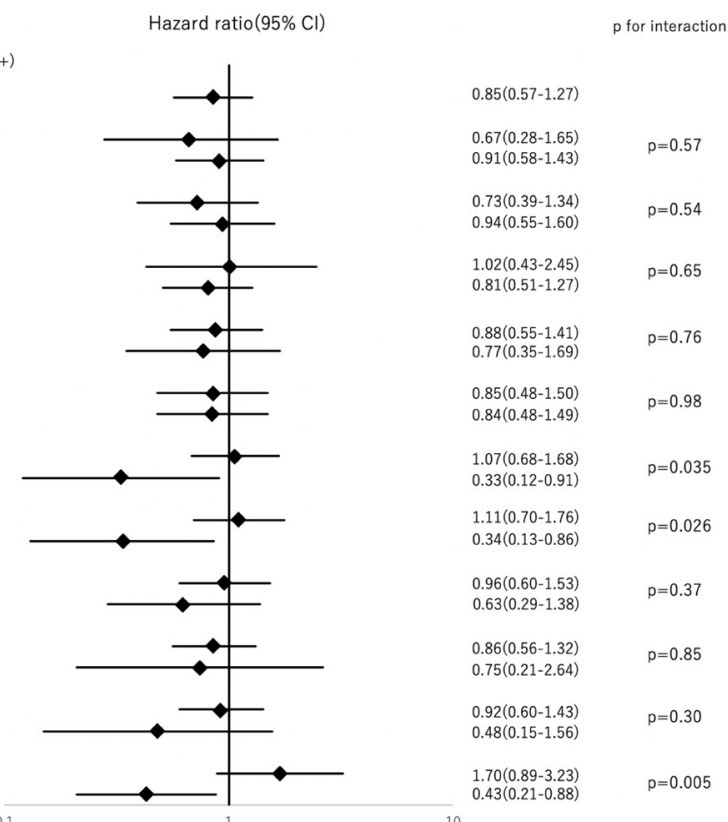

Figure 3 Subgroup analyses for cardiovascular mortality. Beta-blocker $(-)=$ patients without preprocedural beta blockers; beta-blocker $(+)=$ patients with preprocedural beta blockers. Forest plot representing the HRs of cardiovascular mortality in patients with beta-blocker administration compared with patients without, stratified by preprocedural characteristics. AF, atrial fibrillation; AR, aortic regurgitation; BNP, brain natriuretic peptide; CABG, coronary artery bypass grafting; CAD, coronary artery disease; CKD, chronic kidney disease; LVEF, left ventricular ejection fraction; MR, mitral regurgitation; PAD, peripheral artery disease.

\section{DISCUSSION}

The optimal medical therapy for patients undergoing TAVR remains unknown. The main findings of our study showed that the administration of beta blockers to patients undergoing TAVR was associated with a lower incidence of in-hospital congestive heart failure and cardiovascular mortality in specific groups of patients (patients with a history of CABG, presence of PAD, BNP $\geq 400 \mathrm{pg} / \mathrm{mL}$, and post-LVEF $<50 \%$ ). To our knowledge, the present study is the first to identify the association of beta blockers and clinical outcomes after TAVR.

Apart from some trial demonstrations of survival benefits of beta blockers in patients with heart failure with reduced ejection fraction (HFrEF), ${ }^{17-19}$ there are few reports describing the effect of beta blockers on patients undergoing TAVR. An observational study reported that the absence of beta blockers was an independent predictive factor of death following TAVR in patients with a history of chest irradiation. ${ }^{20}$

Two remaining and frequent complications of TAVR are PVL and pacemaker implantation. Administration of beta blockers is considered harmful in patients with AR because of a longer diastolic period. Additionally, beta blockers suppress atrioventricular conduction. Therefore, there was concern that beta-blocker administration would increase the risk and impact of these complications. However, there was no significant difference in PVL degree and new permanent pacemaker implantation rate between patients with and without beta-blocker administration in this study. On the contrary, Younis et al reported that beta-blocker discontinuation was associated with an increased risk of high degree AV block or AF among patients with TAVR. ${ }^{21}$

In this study, beta blockers were associated with a lowered non-cardiovascular mortality in patients with COPD. It was assumed that beta blockers were contraindicated in patients with COPD because of potential exacerbation. Recently, beta-blocker use in patients with COPD was associated with decrease in all-cause mortality and exacerbation rate. ${ }^{22}$ However, these results should not be overstated and are beyond the scope of this study.

Blessberger et al reported that there was no clear evidence of the prevention of beta blockers on congestive heart failure after cardiac surgery. ${ }^{23}$ However, they also reported that perioperative beta-blocker administration reduces the risk of ventricular and supraventricular arrhythmias. These findings may have led to a lower incidence of in-hospital congestive heart failure among patients treated with beta blockers than among those not treated with beta blockers.

All specific groups identified in this study are at high risk of heart failure or cardiovascular event. Patients undergoing TAVR with a history of CABG, presence of $\mathrm{PAD}$, high BNP levels or LVEF $<50 \%$ had high mortality rates. ${ }^{24-27}$ The possible benefits of beta blockers for highrisk patients with heart failure or cardiovascular events could be a potential explanation for the association of a low cardiovascular mortality with beta-blocker administration in these groups of patients. The efficacy of beta blockers in the treatment of ischaemic heart disease and heart failure has been established. Patients with PAD have a high possibility of polyvascular disease, such as 


\section{Patients without previous CABG}

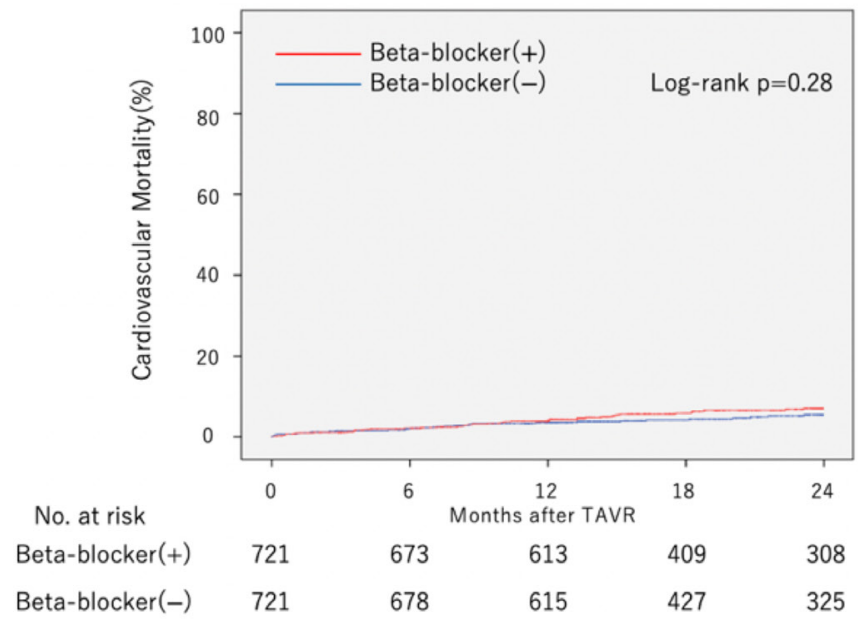

\section{Patients without PAD}

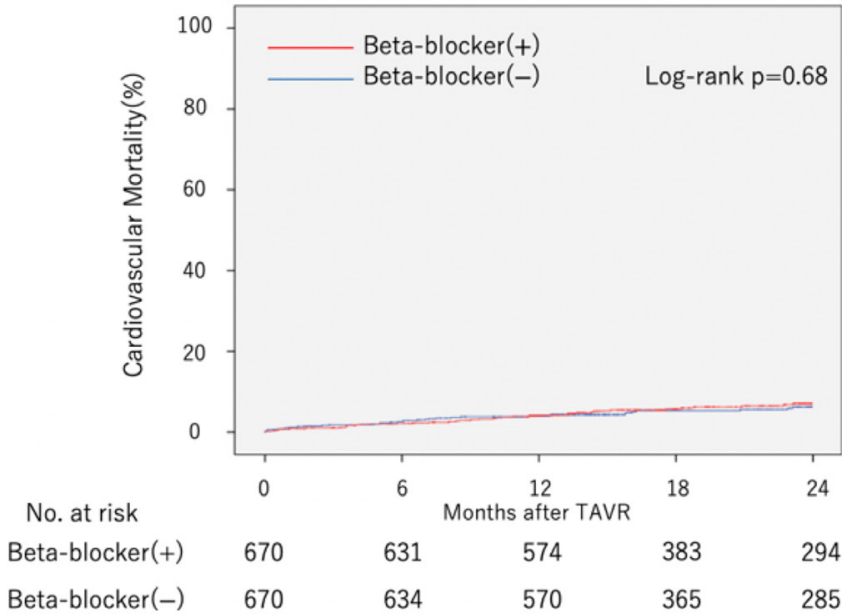

\section{Patients with BNP $<400 \mathrm{pg} / \mathrm{ml}$}

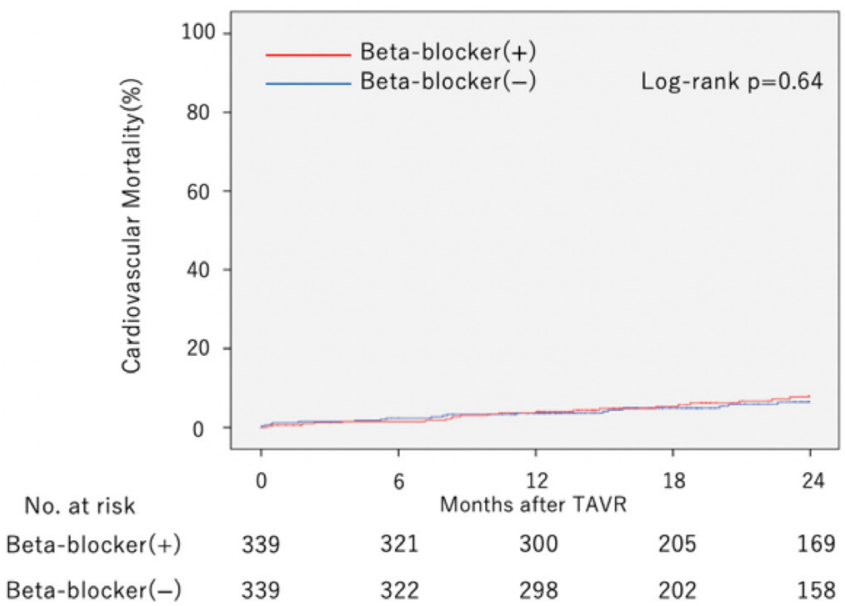

Patients with previous CABG

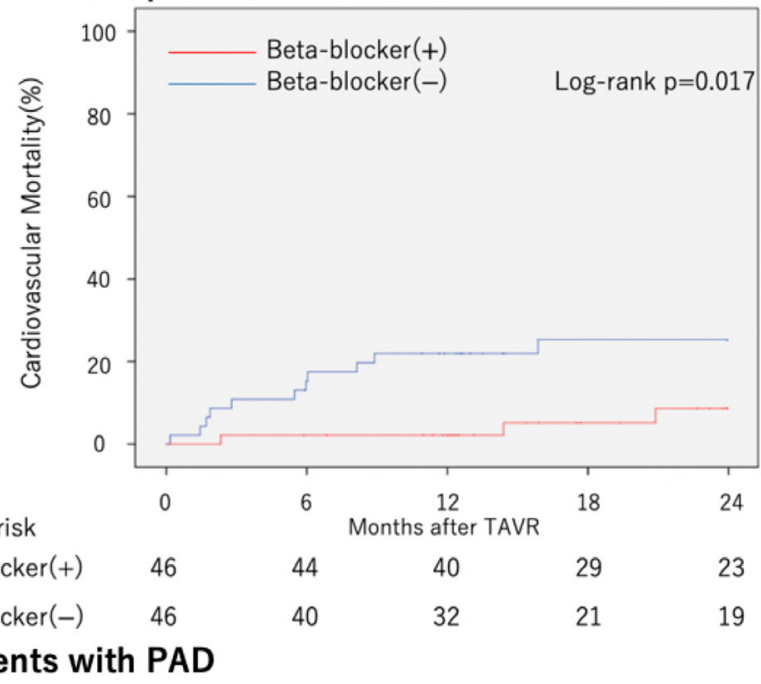

\section{Patients with PAD}

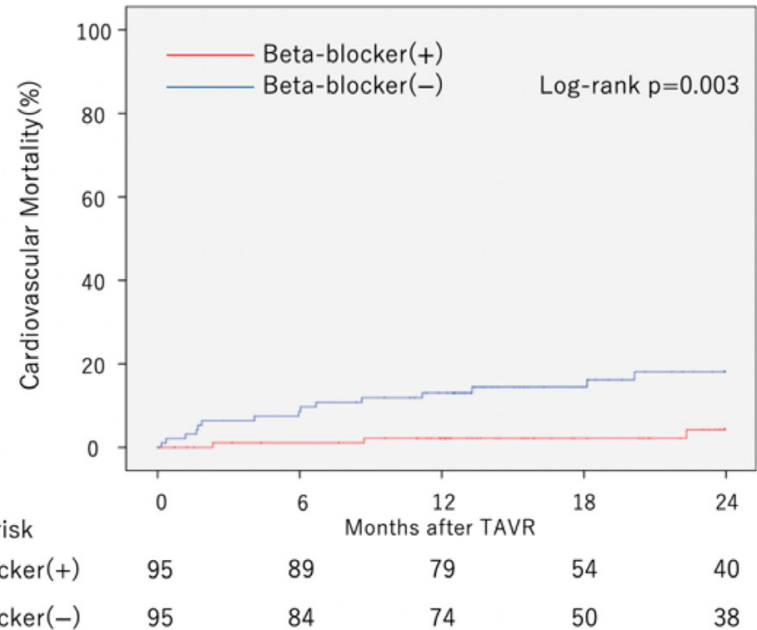

Patients with BNP $\geq 400 \mathrm{pg} / \mathrm{ml}$

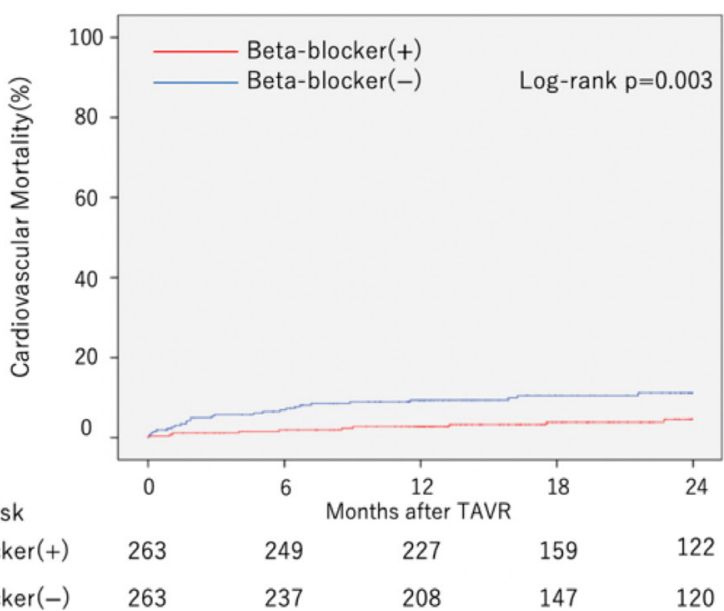

Figure 4 Cardiovascular mortality in subgroups. Kaplan-Meier curve of cardiovascular mortality in patient with and without a history of coronary artery bypass grafting (CABG), with and without presence of peripheral artery disease (PAD), with brain natriuretic peptide $(B N P)<400 \mathrm{pg} / \mathrm{mL}$ and $\geq 400 \mathrm{pg} / \mathrm{mL}$. TAVR, transcatheter aortic valve replacement.

CAD and cerebrovascular disease. In addition, Satiroglu et al reported that the lesion of CAD in patients with PAD was often more severe than that in patients without PAD ${ }^{28}$ For that reason, beta blockers may be effective on patients with PAD undergoing TAVR. Some prior studies have shown that beta-blocker therapy was associated with a low risk of mortality in these patients. ${ }^{17-19} 2930$

In this study, there was no association between the presence and absence of beta-blocker administration in cardiovascular mortality in patients with pre-LVEF 


\begin{tabular}{|c|c|c|c|c|c|c|}
\hline \multirow[t]{2}{*}{ Subgroup } & \multirow[t]{2}{*}{ No. of patients } & \multicolumn{2}{|c|}{ No. of event/total no. of patients } & \multirow{2}{*}{ Hazard ratio $(95 \% \mathrm{Cl})$} & & \multirow[t]{2}{*}{$p$ for interactior } \\
\hline & & Beta-blocker(-) & Beta-blocker $(+)$ & & & \\
\hline Overall & 1558 & $83 / 779$ & $71 / 779$ & & $0.84(0.61-1.16)$ & \multirow{3}{*}{$p=0.51$} \\
\hline Age $<80 y r s$ & 221 & $14 / 113$ & $9 / 108$ & & $0.64(0.28-1.48)$ & \\
\hline Age $\geqq 80 y r s$ & 1337 & $69 / 666$ & $62 / 671$ & - & $0.88(0.63-1.24)$ & \\
\hline Male & 471 & $34 / 232$ & $22 / 239$ & & $0.60(0.35-1.03)$ & \multirow{2}{*}{$p=0.13$} \\
\hline Female & 1087 & $49 / 547$ & $49 / 540$ & & $1.01(0.68-1.50)$ & \\
\hline $\mathrm{BMI}<20 \mathrm{~kg} / \mathrm{m}^{2}$ & 452 & $33 / 223$ & $31 / 229$ & 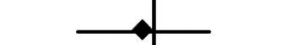 & $0.93(0.57-1.51)$ & \multirow{2}{*}{$p=0.63$} \\
\hline $\mathrm{BMI} \geq 20 \mathrm{~kg} / \mathrm{m}^{2}$ & 1106 & $50 / 506$ & $40 / 510$ & & $0.79(0.52-1.19)$ & \\
\hline NYHA 1 or 2 & 715 & $32 / 355$ & $21 / 360$ & + & $0.63(0.37-1.10)$ & \multirow{2}{*}{$p=0.21$} \\
\hline NYHA 3 or 4 & 843 & $51 / 424$ & $50 / 419$ & & $0.98(0.67-1.45)$ & \\
\hline CKD - & 428 & $23 / 217$ & $13 / 211$ & - & $0.57(0.29-1.13)$ & \multirow{2}{*}{$p=0.21$} \\
\hline CKD+ & 1130 & $60 / 562$ & $58 / 568$ & - & $0.94(0.66-1.35)$ & \\
\hline PAD- & 1308 & $69 / 655$ & $50 / 653$ & & $0.72(0.50-1.03)$ & \multirow{2}{*}{$p=0.27$} \\
\hline PAD+ & 250 & $12 / 124$ & $21 / 126$ & & $1.44(0.73-2.83)$ & \\
\hline COPD- & 1306 & $56 / 644$ & $60 / 662$ & 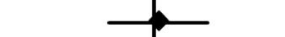 & $1.04(0.72-1.49)$ & \multirow{2}{*}{$p=0.035$} \\
\hline COPD+ & 252 & $27 / 135$ & $11 / 117$ & - & $0.44(0.22-0.89)$ & \\
\hline $\begin{array}{l}\text { Alb }<3.5 \mathrm{~g} / \mathrm{dl} \\
\text { Alb } \geq 3.5 \mathrm{~g} / \mathrm{dl}\end{array}$ & $\begin{array}{r}388 \\
1170\end{array}$ & $\begin{array}{l}33 / 192 \\
50 / 587\end{array}$ & $\begin{array}{l}35 / 196 \\
36 / 583\end{array}$ & - & $\begin{array}{l}1.02(0.63-1.63) \\
0.71(0.46-1.09)\end{array}$ & $p=0.07$ \\
\hline CFS 1-4 & 1179 & $50 / 589$ & $43 / 590$ & & $0.83(0.55-1.25)$ & \multirow{4}{*}{$p=0.60$} \\
\hline CFS 5,6 & 324 & 28/161 & $20 / 163$ & 一 & $0.71(0.40-1.27)$ & \\
\hline $\mathrm{CFS} \geq 7$ & 55 & $5 / 29$ & $8 / 26$ & & $1.86(0.61-5.68)$ & \\
\hline & & & 0. & 1 & & \\
\hline
\end{tabular}

Figure 5 Subgroup analyses for non-cardiovascular mortality. Forest plot representing the HRs of non-cardiovascular mortality in patients with beta-blocker administration compared with patients without, stratified by preprocedural characteristics. BMI, body mass index; CFS, Clinical Frail Score; CKD, chronic kidney disease; COPD, chronic obstructive pulmonary disease; NYHA, New York Heart Association; PAD, peripheral artery disease.

$<50 \%$ or $\geq 50 \%$, although beta-blocker administration was associated with a lower cardiovascular mortality among patients with post-LVEF $<50 \%$. This result may suggest that beta blockers are effective in patients with LVEF $<50 \%$ even after severe AS improvement by TAVR. Patients with LVEF $<50 \%$ included those with HFrEF and with mid-range HFEF (HFmEF). A recent meta-analysis showed that beta blockers reduced cardiovascular mortality in patients with HFrEF and HFmEF. ${ }^{31}$

In this study, we found that beta blockers were not associated with the risk of increased complications and non-cardiovascular mortality. Additionally, we identified the association with beta blockers and clinical outcomes. The optimal medical therapy for patients who undergo TAVR would be important because the indications for TAVR are expanding and the number of these patients is increasing. However, this study could not identify the doses and types of beta blockers. Prospective studies are needed to evaluate these issues.

\section{Study limitations}

This study has several limitations. First, it was a nonrandomised, retrospective study using data from a prospective multicentre cohort registry including a limited number of patients; however, this cohort is representative of real-world practice. Further studies with a larger number of patients are ongoing. Second, the definition of in-hospital congestive heart failure is unique to this registry. Additionally, no information was available on the amounts, types of infusion or drugs used during the procedure that may affect the onset of congestive heart failure. The result of low incidence of in-hospital congestive heart failure is beyond the scope of the effect of beta blockers because the definition includes mechanical support for heart failure, such as IABP and ECMO. In addition, inotropic agents and mechanical support were also used not only for heart failure but also for the cardiogenic shock management. In-hospital congestive heart failure did not include the cases in which inotropic agents or mechanical support was used for other than heart failure. However, the reasons for the use of inotropic agents or mechanical support were site reported from the participating institutions. The diagnosis of heart failure was left to the discretion of the clinicians in each participating institution. Third, no information regarding the dose or period of administration, time schedule or type of beta blockers was included. There was not enough information of medication status at follow-up. In randomised controlled trials, carvedilol, bisoprolol or metoprolol succinate reduce all-cause mortality in patients with HFrEF. ${ }^{17-19}$ Additionally, the effect of beta blockers is dose dependent. ${ }^{32}$ Fourth, there was no information on the blood pressure and heart rate of patients involved in this study. A low heart rate is associated with good prognosis in patients with heart 
A

\section{Pre-procedural LVEF $\geq 50 \%$}

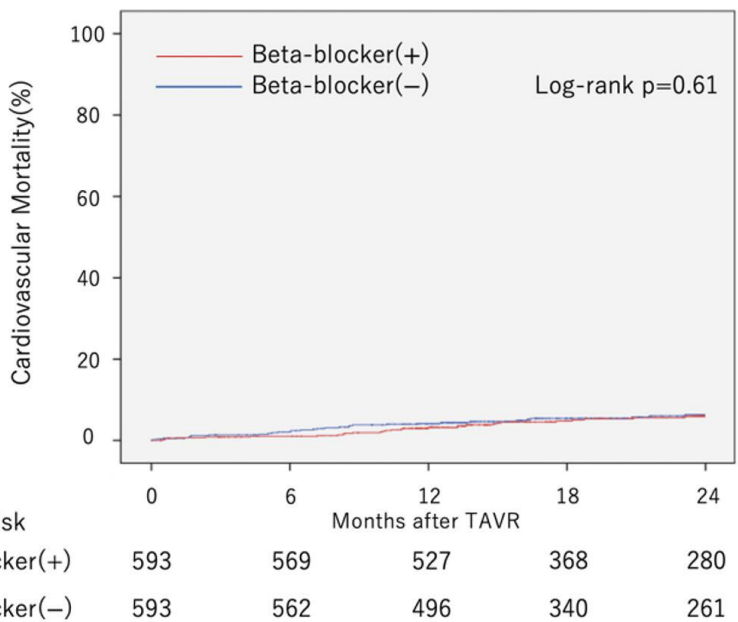

B

Post-procedural LVEF $\geq 50 \%$

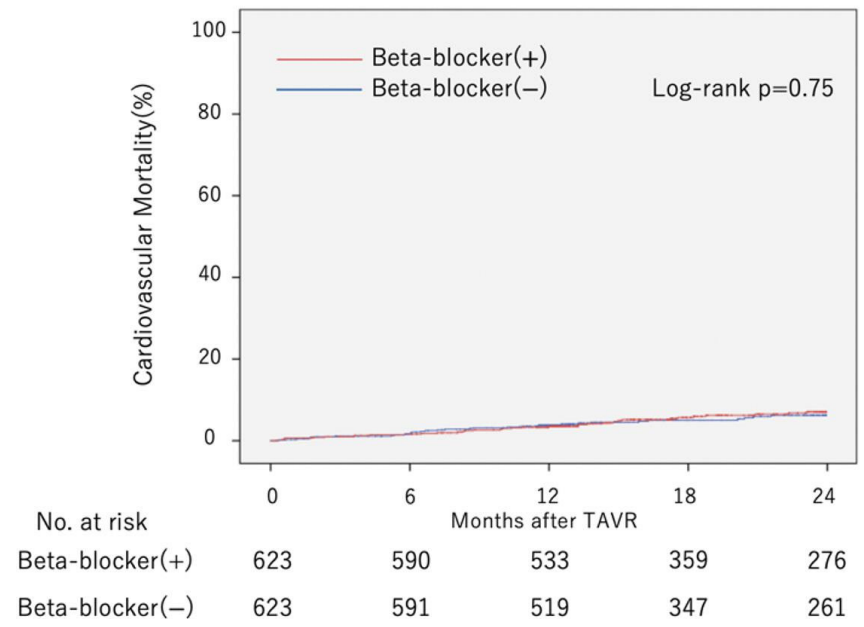

Pre-procedural LVEF $<50 \%$

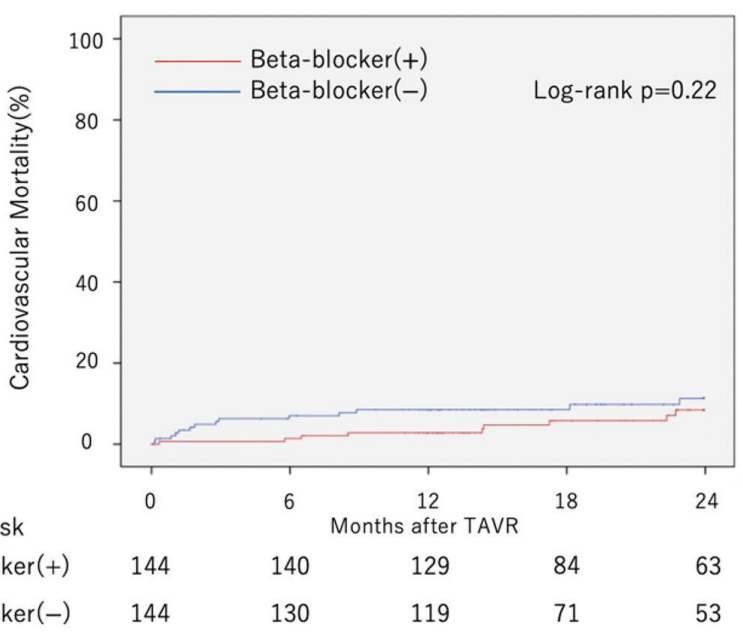

Post-procedural LVEF $<50 \%$

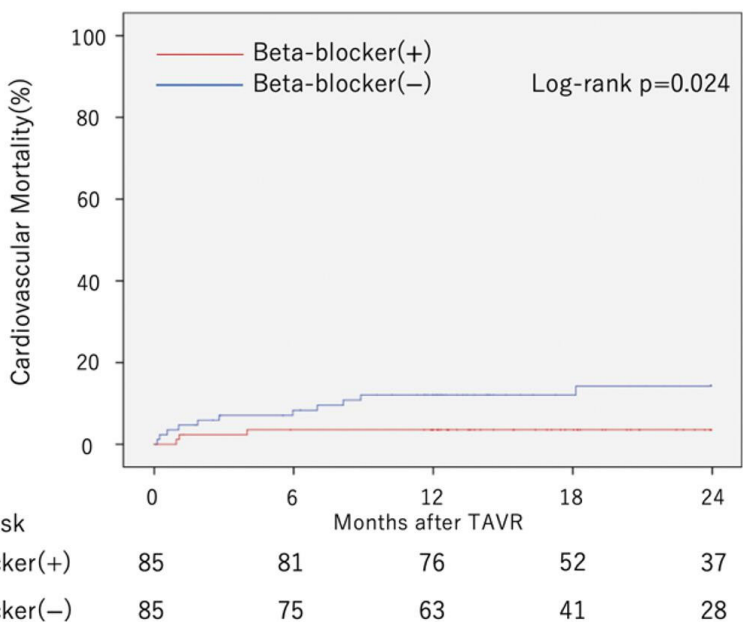

Figure 6 Cardiovascular mortality stratified by left ventricular ejection fraction (LVEF). Kaplan-Meier curve of cardiovascular mortality in patient with preprocedural LVEF $\geq 50 \%$ or $<50 \%$ (A), postprocedural LVEF $\geq 50 \%$ or $<50 \%$ (B). TAVR, transcatheter aortic valve replacement.

failure ${ }^{32}$ and it is not recommended to use beta blockers in patients with hypotension or bradycardia. Lastly, there was a possibility that some of the significant results were due to the multiple testing. In addition, the number of the events of secondary outcomes and the event in the subgroups was relatively small. The statistical power may be limited. Therefore, more meticulous studies including larger patients that consider these should be our future targets.

\section{Conclusions}

Preprocedural beta-blocker administration for patients undergoing TAVR was not associated with 2-year cardiovascular and non-cardiovascular mortality in overall, but was associated with a lower risk of 2-year cardiovascular mortality only in patients with a history of CABG, presence of $\mathrm{PAD}, \mathrm{BNP} \geq 400 \mathrm{pg} / \mathrm{mL}$ and post-LVEF $<50 \%$.
These patients may be better prescribed beta blockers. The findings need to be confirmed by randomised trials.

\section{Author affiliations}

${ }^{1}$ Cardiology, Keio University School of Medicine, Shinjuku-ku, Tokyo, Japan

${ }^{2}$ Cardiology, Saiseikai Utsunomiya Hospital, Utsunomiya, Tochigi, Japan

${ }^{3}$ Cardiovascular Surgery, Keio University School of Medicine, Shinjuku-ku, Tokyo, Japan

${ }^{4}$ Cardiology, New Tokyo Hospital, Matsudo, Chiba, Japan

${ }^{5}$ Cardiovascular Medicine, Osaka City General Hospital, Osaka, Osaka, Japan

${ }^{6}$ Cardiology, Saiseikai Yokohama-City Eastern Hospital, Yokohama, Kanagawa, Japan

${ }^{7}$ Cardiology, Sendai Kosei Hospital, Sendai, Miyagi, Japan

${ }^{8}$ Cardiology, Shonan Kamakura General Hospital, Kamakura, Kanagawa, Japan

${ }^{9}$ Cardiology, Kokura Memorial Hospital, Kitakyushu, Fukuoka, Japan

${ }^{10}$ Cardiovascular Surgery, Tokyo Bay Urayasu Ichikawa Iryo Center, Urayasu, Chiba, Japan

${ }^{11}$ Cardiology, Toyama University School of Medicine, Toyama, Toyama, Japan

${ }^{12}$ Cardiology, Ogaki Municipal Hospital, Ogaki, Gifu, Japan

${ }^{13}$ Cardiology, Kishiwada Tokushukai Hospital, Kishiwada, Osaka, Japan 
${ }^{14}$ Cardiology, Teikyo University School of Medicine, Itabashi-ku, Tokyo, Japan

${ }^{15}$ Cardiology, Toyohashi Heart Center, Toyohashi, Aichi, Japan

${ }^{16}$ Cardiology, Nagoya Heart Center, Nagoya, Aichi, Japan

Acknowledgements The authors thank all the OCEAN-TAVI investigators.

Contributors Study conception, design, analysis and interpretation, drafting of the manuscript: TS, NY, HH, HT and KH. Critical revision of the manuscript for important intellectual content: FY, KF, HS, TN, KM, MA, NT, FY, SS, MT, HU, KT, AH, YW, MY and KH. Overall responsible: $\mathrm{KH}$.

Funding The OCEAN-TAVI registry is supported by Edwards Lifesciences, Medtronic and Daiichi-Sankyo company.

Competing interests MY, NT, TN, SS, KM and YW are clinical proctors for Edwards Lifesciences and Medtronic. MA, MT, KT, AH, HS and KH are clinical proctors of Edwards Lifesciences. HU is a clinical proctor for Medtronic.

Patient consent for publication Not required.

Provenance and peer review Not commissioned; externally peer reviewed.

Data availability statement No data are available. The data in this research are deidentified participant data. The data, materials will not be available to researchers for purpose of reproducing the results or replicating the procedure.

Open access This is an open access article distributed in accordance with the Creative Commons Attribution 4.0 Unported (CC BY 4.0) license, which permits others to copy, redistribute, remix, transform and build upon this work for any purpose, provided the original work is properly cited, a link to the licence is given, and indication of whether changes were made. See: https://creativecommons.org/ licenses/by/4.0/.

\section{ORCID iDs}

Tetsuya Saito http://orcid.org/0000-0001-5356-9477

Fumiaki Yashima http://orcid.org/0000-0002-7755-5771

Masanori Yamamoto http://orcid.org/0000-0001-5210-6382

\section{REFERENCES}

1 Nadir MA, Wei L, Elder DHJ, et al. Impact of renin-angiotensin system blockade therapy on outcome in aortic stenosis. J Am Coll Cardiol 2011;58:570-6.

2 Yamamoto K, Yamamoto H, Takeuchi M, et al. Risk factors for progression of degenerative aortic valve disease in the Japanesethe Japanese aortic stenosis study (JASS) prospective analysis. Circ J 2015;79:2050-7.

3 Rossi A, Temporelli PL, Cicoira M, et al. Beta-Blockers can improve survival in medically-treated patients with severe symptomatic aortic stenosis. Int J Cardiol 2015;190:15-17.

4 Hansson NH, Sörensen J, Harms HJ, et al. Metoprolol reduces hemodynamic and metabolic overload in asymptomatic aortic valve stenosis patients: a randomized trial. Circ Cardiovasc Imaging 2017;10:1-9.

5 Makkar RR, Fontana GP, Jilaihawi $\mathrm{H}$, et al. Transcatheter aortic-valve replacement for inoperable severe aortic stenosis. $N$ Engl J Med 2012;366:1696-704.

6 Leon MB, Smith CR, Mack MJ, et al. Transcatheter or surgical aortic-valve replacement in intermediate-risk patients. $N$ Engl J Med 2016;374:1609-20.

7 Reardon MJ, Van Mieghem NM, Popma JJ, et al. Surgical or transcatheter aortic-valve replacement in intermediate-risk patients. N Engl J Med 2017;376:1321-31.

8 Mack MJ, Leon MB, Thourani VH, et al. Transcatheter aortic-valve replacement with a balloon-expandable valve in low-risk patients. $N$ Engl J Med 2019;380:1695-705.

9 Popma JJ, Deeb GM, Yakubov SJ, et al. Transcatheter aortic-valve replacement with a self-expanding valve in low-risk patients. $N$ Engl J Med 2019;380:1706-15.

10 Ochiai T, Saito S, Yamanaka F, et al. Renin-Angiotensin system blockade therapy after transcatheter aortic valve implantation. Heart 2018;104:644-51.

11 Inohara T, Manandhar P, Kosinski AS, et al. Association of reninangiotensin inhibitor treatment with mortality and heart failure readmission in patients with transcatheter aortic valve replacement. JAMA 2018;320:2231-40.
12 Kappetein AP, Head SJ, Généreux P, et al. Updated standardized endpoint definitions for transcatheter aortic valve implantation: the valve academic research Consortium-2 consensus document. Eurolntervention 2012:8:782-95.

13 Lang RM, Badano LP, Mor-Avi V, et al. Recommendations for cardiac chamber quantification by echocardiography in adults: an update from the American Society of echocardiography and the European association of cardiovascular imaging. J Am Soc Echocardiogr 2015;28:e14:1-39.

14 Baumgartner $\mathrm{H}$, Hung J, Bermejo J, et al. Recommendations on the echocardiographic assessment of aortic valve stenosis: a focused update from the European association of cardiovascular imaging and the American Society of echocardiography. J Am Soc Echocardiogr 2017;30:372-92.

15 Maisel A. B-Type natriuretic peptide levels: diagnostic and prognostic in congestive heart failure: what's next? Circulation 2002;105:2328-31.

16 Maisel A, Mueller C, Adams K, et al. State of the art: using natriuretic peptide levels in clinical practice. Eur J Heart Fail 2008;10:824-39.

17 CIBIS-II Investigators nad Committees. The cardiac insufficiency bisoprolol study II (CIBIS-II): a randomised trial. Lancet 1999;353:913.

18 MERIT-HF group. Effect of metoprolol CR / XL in chronic heart failure : Metoprolol CR / XL Randomised Intervention Trial in Congestive Heart Failure. Lancet 2001;353:2001-7.

19 Packer M, Bristow MR, Cohn JN, et al. The effect of carvedilol on morbidity and mortality in patients with chronic heart failure. $N$ Engl J Med 1996;334:1349-55.

20 Bouleti C, Amsallem M, Touati A, et al. Early and late outcomes after trans-catheter aortic valve implantation in patients with previous chest radiation. Heart 2016;102:1044-51.

21 Younis A, Orvin K, Nof E, et al. The effect of periprocedural beta blocker withdrawal on arrhythmic risk following transcatheter aortic valve replacement. Catheter Cardiovasc Interv 2019;93:1361-6.

22 Etminan M, Jafari S, Carleton B, et al. Beta-Blocker use and COPD mortality: a systematic review and meta-analysis. BMC Pulm Med 2012;12:48

23 Blessberger H, Kammler J, Domanovits H, et al. Perioperative beta-blockers for preventing surgery-related mortality and morbidity. Cochrane Database Syst Rev 2018;3:CD004476.

24 Kawashima H, Watanabe $\mathrm{Y}$, Kozuma K, et al. Comparison of midterm outcomes of transcatheter aortic valve implantation in patients with and without previous coronary artery bypass grafting. Heart Vessels 2018;33:1229-37.

25 Abramowitz $\mathrm{Y}$, Chakravarty $\mathrm{T}$, Jilaihawi $\mathrm{H}$, et al. Impact of Preprocedural B-type natriuretic peptide levels on the outcomes after transcatheter aortic valve implantation. Am J Cardiol 2015;116:1904-9.

26 Fanaroff AC, Manandhar P, Holmes DR, et al. Peripheral artery disease and transcatheter aortic valve replacement outcomes: a report from the Society of thoracic Surgeons/American College of cardiology transcatheter therapy registry. Circ Cardiovasc Interv 2017; 10:e005456.

27 Ewe SH, Ajmone Marsan N, Pepi M, et al. Impact of left ventricular systolic function on clinical and echocardiographic outcomes following transcatheter aortic valve implantation for severe aortic stenosis. Am Heart J 2010;160:1113-20.

28 Satiroglu O, Kocaman SA, Karadag Z, et al. Relationship of the angiographic extent of peripheral arterial disease with coronary artery involvement. J Pak Med Assoc 2012;62:644-9.

29 Zhang $\mathrm{H}$, Yuan $\mathrm{X}$, Zhang $\mathrm{H}$, et al. Efficacy of long-term $\beta$-blocker therapy for secondary prevention of long-term outcomes after coronary artery bypass grafting surgery. Circulation 2015;131:2194-201.

30 Feringa $\mathrm{HHH}$, Bax JJ, Hoeks S, et al. A prognostic risk index for long-term mortality in patients with peripheral arterial disease. Arch Intern Med 2007;167:2482-9.

31 Cleland JGF, Bunting KV, Flather MD, et al. Beta-Blockers for heart failure with reduced, mid-range, and preserved ejection fraction: an individual patient-level analysis of double-blind randomized trials. Eur Heart J 2018;39:26-35.

32 Fiuzat M, Wojdyla D, Pina I, et al. Heart Rate or Beta-Blocker Dose? Association With Outcomes in Ambulatory Heart Failure Patients With Systolic Dysfunction: Results From the HF-ACTION Trial. JACC Heart Fail 2016;4:109-15. 